American Journal of Applied Sciences 7 (9): 1264-1276, 2010

ISSN 1546-9239

(C) 2010 Science Publications

\title{
Synthesis of a Robust Multiobserver for the Estimation of Unknown Inputs Using the Piecewise Quadratic Functions
}

\author{
${ }^{1,4}$ Sami Zemmel, ${ }^{2,4}$ Mongi Besbes, ${ }^{2,4}$ Elyes Maherzi and ${ }^{3,4}$ Radhi Mhiri \\ ${ }^{1}$ Department of Physics and Electronics, Faculty of Sciences, Tunis, Tunisia \\ ${ }^{2}$ Department of Engineering Electric, School of Technology and Data Processing, \\ Tunis, Tunisia \\ ${ }^{3}$ University of Sherbrooke, Montréal, Canada \\ ${ }^{4}$ Laboratory of Networks and Machines Electric, \\ National Institute of Sciences Applied and Technologies, Tunis, Tunisia
}

\begin{abstract}
Problem statement: The estimation of states and the unknown inputs of a nonlinear system described by a multimodel are done by a multiobserver. The stabilization of the multiobserver calls upon uses both quadratic and no quadratic functions of Lyapunov. Although the stabilization using the quadratic approach is interesting from the point of view implementation, the step showed its limits for the multimodel. However, the problem paused by the quadratic method lies in the obligation to satisfy several LMI with respect to the same Lyapunov matrix P, these results are shown very conservative. Approach: To reduce the conservatism of the quadratic approach we propose another approach which is exclusively based on Lyapunov piecewise quadratic functions. The conditions obtained by the stabilization of the multiobserver are expressed in term of matrix inequalities with constraints on the matrices rank. Results: The estimation of both states and unknown inputs of a multimodel using the quadratic approach per pieces leads to results less conservative than the quadratic approach. Academic examples illustrate the robustness of the piecewise quadratic approach. Conclusion: In this article we proposed new sufficient conditions of stability of a multiobserver able to the estimation of states and unknown inputs of a nonlinear system describes by a multimodel subjected to the influence of the unknown inputs. The study in was carried out by considering two approaches. The first approach is based on Lyapunov quadratic functions; it is significant to note the great difficulty in finding satisfying results by this approach for the multimodel systems. For this reason we proposed an approach based on piecewise quadratic functions which led to interesting results (proposition 1) and less conservative than the quadratic approach. The conditions suggested in this article concern both the multiobserver stabilization and the estimation of states and the unknown inputs of a multimodel with measurable variables of decision $(\mu \xi(\mathrm{k}))$. The synthesis of a multiobserver with no measurable variables of decision is not approached. This point can constitute an interesting prospect for this study.
\end{abstract}

Key words: Discrete multimodel, unknown input multiobserver, quadratic stabilization, piecewise quadratic functions, unknown input estimation

\section{INTRODUCTION}

The state observation of the nonlinear dynamic systems constitutes a very vast search field having many applications. This is justified by the fact that the state estimation is an important stage, even indispensable, for the synthesis of command laws, for the diagnosis or for the supervision of the industrial process. The basic idea is the substitution of the materials sensor by using non linear observers not only for economical reasons but also to come over on many technological difficulties, particularly when the adequate sensor isn't obtainable. So, the use of this idea for several years has been the replacement of the material sensors by state observers, which allow the rebuilding of intern information (states, unknown inputs and unknown parameters) of a system using its model, known inputs and measured outputs.

Among the solutions brought to the problem of the state estimation and output in the presence of unknown inputs we have two approaches of construction of multiobserver that emerged. The first one supposes a priori knowledge of information about these not measurable inputs; in particular, the filter of Kalman who allows to rebuild the state of the system in the presence of measurement noise which is defined like unknown inputs, by using a priori of statistical knowledge on these noises. The second

Corresponding Author: Sami Zemmel, Department of Physics and Electronics, Faculty of Sciences, Tunis, Tunisia 
approach proceeds either by estimation of the unknown inputs or by their complete elimination from the equations of the system (Akhenak et al., 2003; 2006; Chadli et al., 2009; Darouach et al., 1994). The observers with unknown inputs have attracted the attention of many researchers that of Dassanake et al. (2000) who used unknown input observers to detect and isolate sensor faults in a turbofan engine.

The crucial problem, in the synthesis of the observers with unknown inputs, is the convergence of the estimation error towards zero. Several works used the second method of Lyapunov and their quadratic functions for the stabilization of the estimation error in the case of the linear systems (Moreno, 2001; Floquet and Barbot, 2004) and in the case of the nonlinear systems (Koeing, 2006). However, this method generates very conservative conditions of stability of the observer in particular for certain classes of nonlinear systems such as the systems with parametric uncertainties (Chadli and El Ahajjaji, 2006), the saturated systems and linear systems piecewise, which includes no information about space state partition (Johansson et al., 1999). Whereas, the using of the no quadratic Lyapunov functions like the polyquadratic functions and the piecewise quadratic functions, allows the reduce of the conservatism of the quadratic method and leads to after less pessimistic results for the stabilization and the control of the systems (Jadbabaie, 1999; Johansen, 2000). For this reason, it is interesting to use the piecewise quadratic Lyapunov functions for the stabilization of the estimation error.

Today, the diagnosis of the industrial systems draws the attention of several researchers (Athamena et al., 2007; Kechida and Debbache, 2005; Hakiki et al., 2006). Many methods are published for the diagnosis various classes systems. For the diagnosis and the supervision of a multimodel system were proposed some interesting methods which are based on multiobserver (Dassanake et al., 2000; Marx et al., 2007). For this reason we design in this article a new multiobserver whom can be used for the diagnosis of a system described by a multimodel.

Notation: Throughout the study, the following useful notation is used:

$(\mathrm{X})^{\mathrm{T}}=$ The transpose of the matrix $\mathrm{X}$

$(\mathrm{Y})^{-1}=$ The inverse of the matrix $\mathrm{Y}$

$(Z)^{-}=$The pseudo inverse of the matrix $\mathrm{Z}$

I $=$ The $\mathrm{n} \times \mathrm{n}$ identity matrix

Estimation of state and unknown inputs of a multimodel: The formalization of the estimation problem of state and unknown inputs rests on multimodel approach. The considered system comprises known inputs and unknown inputs. The reconstruction of the non measured system states and its unknown inputs is realized on the base of information generated by a nonlinear observer called to unknown inputs widely widespread for the state estimation of systems.

General structure of the multimodel: The model of system, supposed known, is taken in the following form (Akhenak et al., 2004):

$\left\{\begin{array}{l}x(k+1)=\sum_{i=1}^{M} \mu_{i}(\xi(k))\left(\begin{array}{l}A_{i} x(k)+B_{i} u(k) \\ +R_{i} \bar{u}(k)\end{array}\right) \\ y(k)=C x(k)+F \bar{u}(k)\end{array}\right.$

With:

$$
\left\{\begin{array}{l}
\sum_{\mathrm{i}=1}^{\mathrm{M}} \mu_{\mathrm{i}}(\xi(\mathrm{k}))=1 \\
0 \leq \mu_{\mathrm{i}}(\xi(\mathrm{k})) \leq 1
\end{array} \quad \forall \mathrm{i} \in\{1, \ldots, \mathrm{M}\}\right.
$$

Where:

$\mathrm{x}(\mathrm{k}) \in \mathrm{R}^{\mathrm{n}}=$ The state vector

$\mathrm{u}(\mathrm{k}) \in \mathrm{R}^{\mathrm{m}}=$ The vector of the known inputs

$\overline{\mathrm{u}}(\mathrm{k}) \in \mathrm{R}^{\mathrm{q}}=$ The vector of unknown inputs

$\mathrm{y}(\mathrm{k}) \in \mathrm{R}^{\mathrm{p}}=$ The vector of measurable outputs

For the ith local model $A_{i} \in R^{n \times n}$ is the state matrix, $B_{i} \in R^{n \times m}$ is the matrix of input, $R_{i} \in R^{n \times q}$ is the matrix of influence of the unknown inputs on the state $x(t), \in R^{p \times q}$ is the matrix of influence of the unknown inputs on the output $\mathrm{y}(\mathrm{k})$ with $\operatorname{rank}(\mathrm{F})=\mathrm{q}$ and $\mathrm{C} \in \mathrm{R}^{\mathrm{p}^{\times \mathrm{n}}}$ is the matrix of output. Finally, $\xi(\mathrm{k})$ represents the vector of decision depending on the input and/or the measurable state variables. At every moment, $\mu_{\mathrm{i}}(\xi(\mathrm{k}))$ indicate the degree of activation of each local model for the global model. The activation functions are determined by the geometrical approach (Maherzi et al., 2007).Choosing the number $M$ of local models of this multimodel can be intuitively achieved taking into account the number of modes functioning observed of the system (Gasso et al., 2001; Johansen and Babuska, 2003). However, determining the matrices $A_{i}, B_{i}, C, R_{i}$ and F needs the use of adapted estimation techniques parametric or techniques of linearization (Johansen et al., 2000).

In the following the considered problem concerns both the reconstruction of state variables $\mathrm{x}(\mathrm{k})$ and the unknown inputs $\overline{\mathrm{u}}(\mathrm{k})$, using only the available namely known inputs $\mathrm{u}(\mathrm{k})$ and the measured outputs $\mathrm{y}(\mathrm{k})$.

General structure of the multiobserver: This paragraph clarifies the construction of the 
observer. This last shows an analytical form resulting from the aggregation of the local linear observers (Kim et al., 2006; Patton et al., 1998). This one is particularly adapted for studying the stability and the convergence property of the state reconstruction error. The numerical aspects related to the determination of the gains of the local observers will be also treated. The form of the multiobserver that is able to estimate the state vector and the unknown input of the discrete multimodel (1) has the following structure:

$$
\left\{\begin{array}{l}
\mathrm{z}(\mathrm{k}+1)=\sum_{\mathrm{i}=1}^{\mathrm{M}} \mu_{\mathrm{i}}(\xi(\mathrm{k}))\left(\begin{array}{l}
\mathrm{N}_{\mathrm{i}} \mathrm{z}(\mathrm{k})+\mathrm{G}_{\mathrm{i} 1} \mathrm{u}(\mathrm{k}) \\
+\mathrm{G}_{\mathrm{i} 2}+\mathrm{L}_{\mathrm{i}} \mathrm{y}(\mathrm{k})
\end{array}\right) \\
\hat{\mathrm{x}}(\mathrm{k})=\mathrm{z}(\mathrm{k})-\mathrm{Ey}(\mathrm{k})
\end{array}\right.
$$

It is about a general structure of observer, it is not only, where $\mathrm{N}_{\mathrm{i}} \in \mathrm{R}^{\mathrm{n} \times \mathrm{n}}, \mathrm{G}_{\mathrm{i} 1} \in \mathrm{R}^{\mathrm{n} \times \mathrm{m}}, \mathrm{G}_{\mathrm{i} 2} \in \mathrm{R}^{\mathrm{n}}, \mathrm{L}_{\mathrm{i}} \in \mathrm{R}^{\mathrm{n} \times \mathrm{p}}$ and $\mathrm{E}$ are the gains matrices of the ith local observer with unknown input. The variable $\mathrm{z}(\mathrm{k})$ is an intermediate variable allowing to deduce the estimated value from the state $\widehat{\mathrm{x}}(\mathrm{k})$.

Obviously, the observer uses only the known variables $\mathrm{u}(\mathrm{k})$ and $\mathrm{y}(\mathrm{k}), \overline{\mathrm{u}}(\mathrm{k})$ being not measured. The whole of these matrices must be given with a high degree of accuracy from a numerical point of view in order to guarantee the convergence of the estimated state by the observer towards the real state. For that, let us define the state estimation error:

$\mathrm{e}(\mathrm{k})=\mathrm{x}(\mathrm{k})-\widehat{\mathrm{x}}(\mathrm{k})$

Starting from this definition and by using the expression of $\widehat{\mathrm{x}}(\mathrm{k})$ given by the Eq. 2, the expression of the error becomes:

$\mathrm{e}(\mathrm{k})=\mathrm{Qx}(\mathrm{k})-\mathrm{z}(\mathrm{k})+\mathrm{EF} \overline{\mathrm{u}}(\mathrm{k})$

With:

$$
\mathrm{Q}=\mathrm{I}+\mathrm{EC}
$$

Then, one expresses the temporal evolution of the state error in order to analyze its convergence towards zero. Thus, at time $(\mathrm{k}+1)$, the state estimation error is expressed:

$$
\begin{aligned}
& \mathrm{e}(\mathrm{k}+1)=\sum_{\mathrm{i}=1}^{\mathrm{M}} \mu_{\mathrm{i}}(\xi(\mathrm{k}))\left(\begin{array}{l}
\mathrm{Q}\left(\begin{array}{l}
\mathrm{A}_{\mathrm{i}} \mathrm{x}(\mathrm{k})+\mathrm{B}_{\mathrm{i}} \mathrm{u}(\mathrm{k}) \\
+\mathrm{R}_{\mathrm{i}} \overline{\mathrm{u}}(\mathrm{k})
\end{array}\right) \\
-\mathrm{N}_{\mathrm{i}} \mathrm{z}(\mathrm{k})-
\end{array}\right) \\
& \left.\mathrm{G}_{\mathrm{i} 1} \mathrm{u}(\mathrm{k})-\mathrm{G}_{\mathrm{i} 2}-\mathrm{L}_{\mathrm{i}} \mathrm{y}(\mathrm{k})\right)+\mathrm{EF} \overline{\mathrm{u}}(\mathrm{k}+1)
\end{aligned}
$$

Replacing $\mathrm{y}(\mathrm{k}), \mathrm{z}(\mathrm{k})$ and $\mathrm{e}(\mathrm{k})$ by their respective expressions given by (1-3), the state error takes the form, the state estimation error is written:

$$
\begin{aligned}
& \mathrm{e}(\mathrm{k}+1)=\sum_{\mathrm{i}=1}^{\mathrm{M}} \mu_{\mathrm{i}}(\xi(\mathrm{k}))\left[\mathrm{N}_{\mathrm{i}}(\mathrm{x}(\mathrm{k})-\widehat{\mathrm{x}}(\mathrm{k}))\right. \\
& +\left(\mathrm{QA}_{\mathrm{i}}-\mathrm{N}_{\mathrm{i}} \mathrm{Q}-\mathrm{L}_{\mathrm{i}} \mathrm{C}\right) \mathrm{x}(\mathrm{k}) \\
& +\left(\mathrm{QB}_{\mathrm{i}}-\mathrm{G}_{\mathrm{i} 1}\right) \mathrm{u}(\mathrm{k})+\left(\mathrm{QR}_{\mathrm{i}}-\mathrm{N}_{\mathrm{i}} \mathrm{EF}-\mathrm{L}_{\mathrm{i}} \mathrm{F}\right) \\
& +\mathrm{u}(\mathrm{k})-\mathrm{G}_{\mathrm{i} 2} \\
& +\mathrm{EF} \overline{\mathrm{u}}(\mathrm{k}+1)
\end{aligned}
$$

We assure that:

$$
\mathrm{K}_{\mathrm{i}}=\mathrm{N}_{\mathrm{i}} \mathrm{E}+\mathrm{L}_{\mathrm{i}}
$$

Finally:

$$
\begin{aligned}
\mathrm{e}(\mathrm{k}+1)=\sum_{\mathrm{i}=1}^{\mathrm{M}} \mu_{\mathrm{i}}(\xi(\mathrm{k}))\left(\begin{array}{l}
\mathrm{N}_{\mathrm{i}} \mathrm{e}(\mathrm{k}) \backslash \\
+\left(\mathrm{QA}_{\mathrm{i}}-\mathrm{N}_{\mathrm{i}}-\mathrm{K}_{\mathrm{i}} \mathrm{C}\right) \mathrm{x}(\mathrm{k}) \\
+\left(\mathrm{QB}_{\mathrm{i}}-\mathrm{G}_{\mathrm{i} 1}\right) \mathrm{u}(\mathrm{k}) \\
\left.+\left(\mathrm{QR}_{\mathrm{i}}-\mathrm{K}_{\mathrm{i}} \mathrm{F}\right) \overline{\mathrm{u}}(\mathrm{k})-\mathrm{G}_{\mathrm{i} 2}\right)
\end{array}\right. \\
+\mathrm{EF} \overline{\mathrm{u}}(\mathrm{k}+1)
\end{aligned}
$$

If the following conditions are satisfied:

$\mathrm{N}_{\mathrm{i}}=\mathrm{QA}_{\mathrm{i}}-\mathrm{K}_{\mathrm{i}} \mathrm{C}$

$\mathrm{G}_{\mathrm{i} 1}=\mathrm{QB}_{\mathrm{i}}$

$\mathrm{QR}_{\mathrm{i}}=\mathrm{K}_{\mathrm{i}} \mathrm{F}$

$\mathrm{G}_{\mathrm{i} 2}=0$

$\mathrm{EF}=0$

then the problem of the stabilization of the dynamic error of observation is reduced to the stabilization $\sum_{\mathrm{i}=1}^{\mathrm{M}} \mu_{\mathrm{i}}(\xi(\mathrm{k})) \mathrm{N}_{\mathrm{i}} \mathrm{e}(\mathrm{k}) \quad$ as the following expression indicates:

$\mathrm{e}(\mathrm{k}+1)=\sum_{\mathrm{i}=1}^{\mathrm{M}} \mu_{\mathrm{i}}(\xi(\mathrm{k})) \mathrm{N}_{\mathrm{i}} \mathrm{e}(\mathrm{k})$

The stability conditions of the multiobserver (2) will emerge starting from the conditions from stabilization of the observation error (11). It is important to note that the stability of the local matrices $\mathrm{N}_{\mathrm{i}}(\mathrm{i}=1, \ldots, \mathrm{M})$, does not guarantee the global stability of the matrix $N=\sum_{i=1}^{M} \mu_{i}(\xi(k)) N_{i}$.

\section{MATERIALS AND METHODS}

The stabilization of the estimation error (11) can be made by three methods: 
Quadratic method: This approach is developed in the paper which uses a function of Lyapunov of the form (17) and this last can exist if the inequality (18) having a solution.

Piecewise quadratic method: This second approach is proposed in the pape which uses a function of Lyapunov of the form (31) and this last can exist if the inequality (33) having a solution.

Polyquadratic method: It is another approach which uses a function of Lyapunov of the following form:

$$
\mathrm{V}(\mathrm{e}(\mathrm{k}))=\mathrm{e}(\mathrm{k})^{\mathrm{T}}\left(\sum_{\mathrm{i}=1}^{\mathrm{M}} \mu_{\mathrm{i}}(\xi(\mathrm{k})) \mathrm{P}_{\mathrm{i}}\right) \mathrm{e}(\mathrm{k}), \mathrm{P}_{\mathrm{i}}>0
$$

where, $\left(\mathrm{P}_{\mathrm{i}}, \mathrm{i}=1, \ldots, \mathrm{M}\right)$ are symmetric positive definite matrices.

This last can exist if the following inequality having a solution (Daafouz and Bernussou, 2001):

$$
\left[\begin{array}{cc}
\mathrm{P}_{\mathrm{i}} & \left(\mathrm{P}_{\mathrm{j}} \mathrm{N}_{\mathrm{i}}\right)^{\mathrm{T}} \\
\mathrm{P}_{\mathrm{j}} \mathrm{N}_{\mathrm{i}} & \mathrm{P}_{\mathrm{j}}
\end{array}\right]>0, \forall(\mathrm{i}, \mathrm{j}) \in\{1, \ldots, \mathrm{M}\}
$$

\section{RESULTS AND DISCUSSION}

This part will present the results of two approaches (quadratic approach and piecewise quadratic approach) for the estimation of states and the unknown inputs of a system multimodel.

Unknown input estimation: In the system (2), the unknown input appears with the matrix of influence $\Phi(\mathrm{k})$.

Let us define:

$$
\Phi(\mathrm{k})=\left(\begin{array}{c}
\sum_{\mathrm{i}=1}^{\mathrm{M}} \mu_{\mathrm{i}}(\xi(\mathrm{k})) \mathrm{R}_{\mathrm{i}} \\
\mathrm{F}
\end{array}\right)
$$

To estimate the unknown input, it is necessary that the matrix $\Phi(\mathrm{k})$ is of full column rank and its pseudo inverse $\Phi^{-}(\mathrm{k})$ exists, otherwise this method is not applicable:

$$
\Phi^{-}(\mathrm{k})=\left(\Phi^{\mathrm{T}}(\mathrm{k}) \Phi(\mathrm{k})\right)^{-1} \Phi(\mathrm{k})^{\mathrm{T}}
$$

The unknown input can then be deduced in the following way:

$$
\overline{\overline{\mathrm{u}}}(\mathrm{k})=\Phi^{-}(\mathrm{k})\left(\begin{array}{c}
\hat{\mathrm{x}}(\mathrm{k}+1)-\sum_{\mathrm{i}=1}^{\mathrm{M}} \mu_{\mathrm{i}}(\xi(\mathrm{A})) \\
\left.\mathrm{y}(\mathrm{k})-\mathrm{C}(\mathrm{x})+\mathrm{B}_{\mathrm{i}} \mathrm{u}(\mathrm{k})\right)
\end{array}\right)
$$

We choose $\Phi(\mathrm{k})$ of full column rank, it is to be able to reverse the matrix $\left(\Phi^{\mathrm{T}}(\mathrm{k}) \Phi(\mathrm{k})\right.$.

Remark 1: The asymptotic convergence of $\overline{\overline{\mathrm{u}}}(\mathrm{k})$ towards $\overline{\mathrm{u}}(\mathrm{k})$ is satisfied, if the stabilization of the observation error (11) of the multiobserver (2) and the condition on the rank of the matrix $\Phi(\mathrm{k})$ are verified.

Global convergence of the multiobserver: For the stabilization of the observation error (11), we propose two approaches based on the use of quadratic Lyapunov function in the first step and the piecewise quadratic Lyapunov function in second step.

Global convergence of the multiobserver by the quadratic approach: In this part, the stabilization of the dynamic error (11) is based on the use of a quadratic Lyapunov function of the form:

$\mathrm{V}(\mathrm{e}(\mathrm{k}))=\mathrm{e}(\mathrm{k})^{\mathrm{T}} \mathrm{Pe}(\mathrm{k}), \quad \mathrm{P}>0$

From this function (15) we can study the stability of the observation error (11).

Theorem 1: The system of form $\mathrm{e}(\mathrm{k}+1)=\sum_{\mathrm{i}=1}^{\mathrm{M}} \mu_{\mathrm{i}}(\xi(\mathrm{k})) \mathrm{N}_{\mathrm{i}} \mathrm{e}(\mathrm{k})$ is globally asymptotically stable (Tanaka et al., 1998):

if $\exists \mathrm{P}>0$ such as $\forall \mathrm{i} \in\{1, \ldots, \mathrm{M}\} \mathrm{N}_{\mathrm{i}}^{\mathrm{T}} \mathrm{PN}_{\mathrm{i}}-\mathrm{P}<0$

Thus, constraints (18) and (10) allow the complete synthesis of multiobserver (2) for the multimodel (1).

Theorem 2: The state estimation error between the multimodel (1) and the unknown input multiobserver (2) converges globally asymptotically towards zero if there exists matrices $\mathrm{p}>0, \mathrm{~S}$ and $\mathrm{W}_{\mathrm{i}}$ such that the following conditions hold $\forall \mathrm{i} \in\{1, \ldots, \mathrm{M}\}$ (Chadli et al., 2009):

$$
\begin{aligned}
& \left(\begin{array}{cc}
\mathrm{P} & \left(\mathrm{PA}_{\mathrm{i}}+\mathrm{SCA}_{\mathrm{i}}-\mathrm{W}_{\mathrm{i}} \mathrm{C}\right)^{\mathrm{T}} \\
\mathrm{PA}_{\mathrm{i}}+\mathrm{SCA}_{\mathrm{i}}-\mathrm{W}_{\mathrm{i}} \mathrm{C} & \mathrm{P}
\end{array}\right)>0 \\
& (\mathrm{P}+\mathrm{SC}) \mathrm{R}_{\mathrm{i}}=\mathrm{W}_{\mathrm{i}} \mathrm{F}
\end{aligned}
$$

$\mathrm{SF}=0$

Multiobserver (2) is then completely defined by:

$\mathrm{E}=\mathrm{P}^{-1} \mathrm{~S}$

$\mathrm{G}_{\mathrm{i} 1}=\left(\mathrm{I}+\mathrm{P}^{-1} \mathrm{SC}\right) \mathrm{B}_{\mathrm{i}}$ 


$$
\mathrm{G}_{\mathrm{i} 2}=0
$$

$$
\mathrm{N}_{\mathrm{i}}=\left(\mathrm{I}+\mathrm{P}^{-1} \mathrm{SC}\right) \mathrm{A}_{\mathrm{i}}-\mathrm{P}^{-1} \mathrm{~W}_{\mathrm{i}} \mathrm{C}
$$

$\mathrm{L}_{\mathrm{i}}=\mathrm{P}^{-1} \mathrm{~W}_{\mathrm{i}}-\mathrm{N}_{\mathrm{i}} \mathrm{E}$

Proof: Using Eq. 18, the hypothesis $\mathrm{p}>0$ and using the Schur complement, one can easily deduce that:

$$
\left(\begin{array}{cc}
\mathrm{P} & \left(\mathrm{PN}_{\mathrm{i}}\right)^{\mathrm{T}} \\
\mathrm{PN}_{\mathrm{i}} & \mathrm{P}
\end{array}\right)>0
$$

After using Eq. 10a and 10c, the preceding inequality becomes:

$$
\begin{aligned}
& \left(\begin{array}{cc}
\mathrm{P} & \left(\mathrm{PA}_{\mathrm{i}}+\mathrm{PECA}_{\mathrm{i}}-\mathrm{PK}_{\mathrm{i}} \mathrm{C}\right)^{\mathrm{T}} \\
\mathrm{PA}_{\mathrm{i}}+\mathrm{PECA}_{\mathrm{i}}-\mathrm{PK}_{\mathrm{i}} \mathrm{C} & \mathrm{P}
\end{array}\right) \\
& >0
\end{aligned}
$$

However, this last inequality (22) is a bilinear matrix inequality BMI in synthesis variables $\mathrm{P}, \mathrm{E}$ and $\mathrm{K}_{\mathrm{i}}$. In order to convert these conditions into an LMI formulation, we consider the following changes of variables:

$\mathrm{W}_{\mathrm{i}}=\mathrm{PK}_{\mathrm{i}}$

$\mathrm{S}=\mathrm{PE}$

After using the new variables of Eq. 23 and 24, inequality (22) becomes:

$$
\left(\begin{array}{cc}
\mathrm{P} & \left(\mathrm{PA}_{\mathrm{i}}+\mathrm{SCA}_{\mathrm{i}}-\mathrm{W}_{\mathrm{i}} \mathrm{C}\right)^{\mathrm{T}} \\
\mathrm{PA}_{\mathrm{i}}+\mathrm{SCA}_{\mathrm{i}}-\mathrm{W}_{\mathrm{i}} \mathrm{C} & \mathrm{P}
\end{array}\right)>0
$$

The two equalities constraints (19b) and (19c) are obtained by pre-multiplying the last two constraints $(10 \mathrm{e})$ and $(10 \mathrm{~g})$ by $\mathrm{p}>0$ with the change of variable (23) and (24):

$$
\begin{aligned}
& \left\{\begin{array} { l } 
{ \mathrm { PQR } _ { \mathrm { i } } = \mathrm { PK } _ { \mathrm { i } } \mathrm { F } } \\
{ \mathrm { PEF } = 0 }
\end{array} \Rightarrow \left\{\begin{array}{l}
(\mathrm{P}+\mathrm{SC}) \mathrm{R}_{\mathrm{i}}=\mathrm{W}_{\mathrm{i}} \mathrm{F} \\
\mathrm{SF}=0
\end{array}\right.\right. \\
& \forall \mathrm{i} \in\{1, \ldots, \mathrm{M}\}
\end{aligned}
$$

Therefore classical numerical tools may be used to solve LMI problem (19a) subject to linear equality constraints (19b) and (19c). After having solved this problem, the different gains matrices defining the multiobserver (2) $\mathrm{N}_{\mathrm{i}}, \mathrm{L}_{\mathrm{i}}, \mathrm{G}_{\mathrm{i} 1}, \mathrm{G}_{\mathrm{i} 2}$ and $\mathrm{E}$ can be deduced from the knowledge of $\mathrm{P}, \mathrm{S}$ and $\mathrm{W}_{\mathrm{i}}$ as given in equations (20). This completes the proof.

Determination of the multiobserver gain matrices: To determine the multiobserver (2) gain matrices by quadratic approach, we propose to follow the steps of the following algorithm:

Step 1: Determination of the matrices $\mathrm{P}, \mathrm{S}$ and $\mathrm{W}_{\mathrm{i}}$ $\forall \mathrm{i} \in\{1, \ldots, \mathrm{M}\}$.

We solve the Linear Matrix Inequalities (19a) in synthesis variables $\mathrm{P}, \mathrm{S}$ and $\mathrm{W}_{\mathrm{i}}$ subject to linear equality constraints (19b) and (19c). This problem can be solved by LMITOOL (Vandenberghe and Boyd, 1996).

Step 2: Determination of the gains matrices $\mathrm{N}_{\mathrm{i}}, \mathrm{L}_{\mathrm{i}}$, $\mathrm{G}_{\mathrm{i} 1}, \mathrm{G}_{\mathrm{i} 2}$ and $\mathrm{E} \forall \mathrm{i} \in\{1, \ldots, \mathrm{M}\}$.

After the knowledge of the matrices $\mathrm{P}, \mathrm{S}$ and $\mathrm{W}_{\mathrm{i}}$, we determine the other gains matrices of Eq. 20 defining the multiobserver (2).

Remark 2: If $\mathrm{F}$ is a scalar, we can deduce the following relations $\forall \mathrm{i} \in\{1, \ldots, \mathrm{M}\}$ :

$\mathrm{S}=0$

$\mathrm{E}=0$

$\mathrm{Q}=\mathrm{I}$

$\mathrm{G}_{\mathrm{i} 1}=\mathrm{B}_{\mathrm{i}}$

$\mathrm{G}_{\mathrm{i} 2}=0$

$\mathrm{N}_{\mathrm{i}}=\mathrm{A}_{\mathrm{i}}-\mathrm{P}^{-1} \mathrm{~W}_{\mathrm{i}} \mathrm{C}$

$\mathrm{L}_{\mathrm{i}}=\mathrm{P}^{-1} \mathrm{~W}_{\mathrm{i}}$

$\mathrm{R}_{\mathrm{i}}=\mathrm{P}^{-1} \mathrm{~W}_{\mathrm{i}} \mathrm{F}$

Simulation examples: Two examples are presented in order illustrate the utilization limits of the quadratic approach. The first is an academic example and the second describes the conservatism of this approach.

An academic example: Consider the following multiple model:

$$
\left\{\begin{aligned}
\mathrm{x}(\mathrm{k}+1) & =\sum_{\mathrm{i}=1}^{2} \mu_{\mathrm{i}}(\xi(\mathrm{k}))\left(\begin{array}{l}
\mathrm{A}_{\mathrm{i}} \mathrm{x}(\mathrm{k})+\mathrm{B}_{\mathrm{i}} \mathrm{u}(\mathrm{k}) \\
+\mathrm{R}_{\mathrm{i}} \overline{\mathrm{u}}(\mathrm{k})
\end{array}\right) \\
\mathrm{y}(\mathrm{k}) & =\mathrm{Cx}(\mathrm{k})+\mathrm{Fu}(\mathrm{k})
\end{aligned}\right.
$$

With:

$$
x=\left(\begin{array}{l}
x_{1} \\
x_{2} \\
x_{3}
\end{array}\right) \text { and } y=\left(\begin{array}{l}
y_{1} \\
y_{2}
\end{array}\right)
$$

The activation functions are the following form: 
Am. J. Applied Sci., 7 (9): 1264-1276, 2010

$\left\{\begin{array}{l}\mu_{1}(\mathrm{u}(\mathrm{k}))=\frac{1-\tanh (\mathrm{u}(\mathrm{k}))}{2} \\ \mu_{2}(\mathrm{u}(\mathrm{k}))=1-\mu_{1}(\mathrm{u}(\mathrm{k}))\end{array}\right.$

The numerical values of the matrices are the following:

$$
\begin{aligned}
& \mathrm{A}_{1}=\left(\begin{array}{ccc}
-0.3 & 0.2 & 0.3 \\
0.3 & 0 & 0.5 \\
0.2 & 0.1 & 0.6
\end{array}\right), \mathrm{A}_{2}=\left(\begin{array}{ccc}
0.6 & -0.5 & 0.2 \\
-0.4 & 0.1 & 0.3 \\
0.1 & 0.2 & 0.3
\end{array}\right), \\
& \mathrm{B}_{1}=\left(\begin{array}{c}
1 \\
1 \\
0.5
\end{array}\right), \mathrm{B}_{2}=\left(\begin{array}{c}
1 \\
1.25 \\
0.5
\end{array}\right) \\
& \mathrm{C}=10^{-2}\left(\begin{array}{ccc}
0 & 1 & 0 \\
-1 & 1 & 1
\end{array}\right), \\
& \mathrm{R}_{1}=\left(\begin{array}{c}
39.86 \\
-23.30 \\
26.85
\end{array}\right), \mathrm{R}_{2}=\left(\begin{array}{c}
6.9 \\
60.46 \\
-1.51
\end{array}\right), \mathrm{F}=\left(\begin{array}{c}
-1 \\
1
\end{array}\right)
\end{aligned}
$$

By using the quadratic approach, the numerical values of all gain matrices are as follows:

$$
\begin{aligned}
& \mathrm{P}=\left(\begin{array}{ccc}
79.7 & -0.26 & 3.41 \\
-0.26 & 71.91 & -7.94 \\
3.41 & -7.94 & 78.06
\end{array}\right) \\
& \mathrm{W}_{1}=10^{3}\left(\begin{array}{cc}
-0.80 & 2.45 \\
2.49 & 0.57 \\
-0.79 & 1.61
\end{array}\right), \quad \mathrm{W}_{2}=10^{3}\left(\begin{array}{cc}
-2.06 & -1.51 \\
-1.92 & 2.45 \\
1.02 & 0.46
\end{array}\right) \\
& \mathrm{S}=\left(\begin{array}{cc}
18.92 & 18.92 \\
20.74 & 20.74 \\
6.12 & 6.12
\end{array}\right), \quad \mathrm{N}_{1}=\left(\begin{array}{ccc}
0.0024 & 0.0007 & 0.0032 \\
0.4076 & -0.0413 & 0.3996 \\
0.4057 & -0.0405 & 0.3967
\end{array}\right) \text {, } \\
& \mathrm{N}_{2}=\left(\begin{array}{ccc}
0.4040 & -0.0402 & 0.3946 \\
-0.0512 & 0.0054 & -0.0506 \\
0.2022 & -0.0200 & 0.1972
\end{array}\right) \\
& \mathrm{L}_{1}=\left(\begin{array}{cc}
-9.7495 & 29.9794 \\
33.7870 & 10.3039 \\
-6.4608 & 20.3391
\end{array}\right), \quad \mathrm{L}_{2}=\left(\begin{array}{cc}
-26.5981 & -19.4174 \\
-25.5211 & 35.2852 \\
11.6825 & 10.2843
\end{array}\right) \text {, } \\
& \mathrm{G}_{11}=\left(\begin{array}{l}
1.0035 \\
1.0045 \\
0.5015
\end{array}\right), \mathrm{G}_{21}=\left(\begin{array}{l}
1.0047 \\
1.2560 \\
0.5020
\end{array}\right)
\end{aligned}
$$

Figure 1a and $\mathrm{b}$ represent the time evolution of known inputs $\mathrm{u}(\mathrm{k})$ and unknown inputs $\overline{\mathrm{u}}(\mathrm{k})$. Figure 2 shows, on the same graph, the evolution of the unknown input $\overline{\mathrm{u}}(\mathrm{k})$ and its estimate $\overline{\mathrm{u}}(\mathrm{k})$. Figure 3 represent the state estimation error with the initial conditions $\quad \mathrm{x}_{0}=\left(\begin{array}{lll}1 & 0 & 0\end{array}\right)^{\mathrm{T}} \quad$ and $\quad \widehat{\mathrm{x}}_{0}=\left(\begin{array}{lll}0 & 0 & 0\end{array}\right)^{\mathrm{T}}$. Excepted around the time origin, the unknown signal estimated perfectly matches the true one.

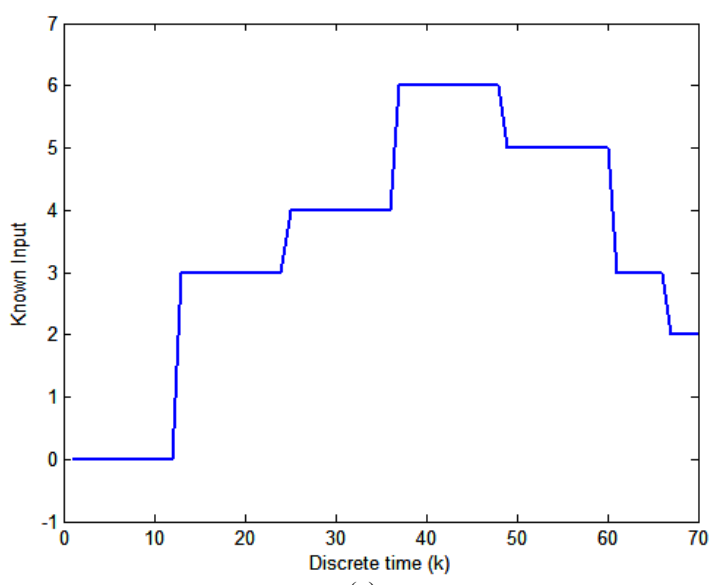

(a)

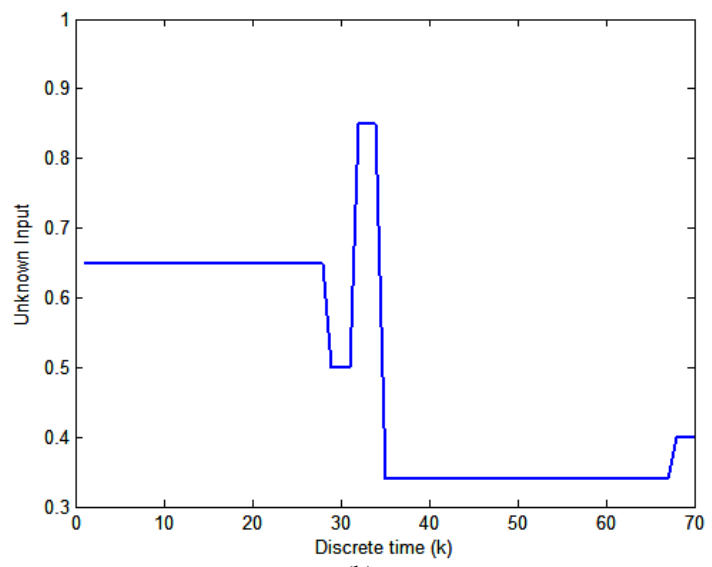

(b)

Fig.1: (a) Input known $\mathrm{u}(\mathrm{k})$ and (b) $\overline{\mathrm{u}}(\mathrm{k})$ input unknown

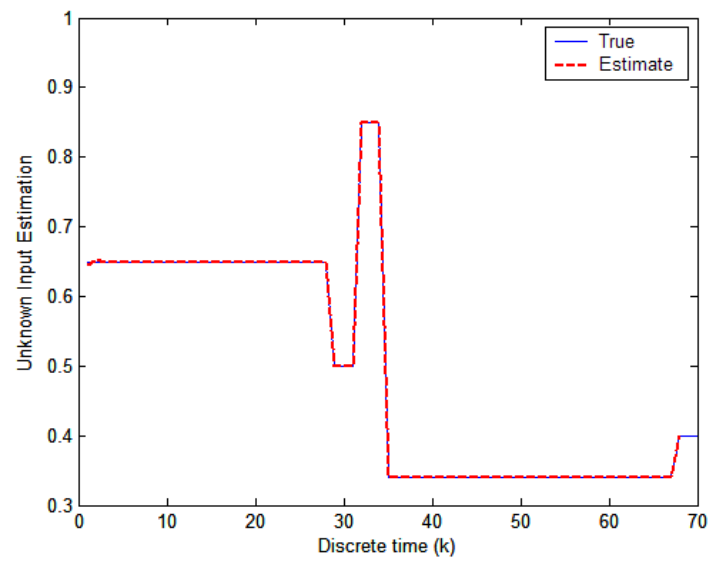

Fig. 2: $\overline{\mathrm{u}}(\mathrm{k})$ and $\overline{\mathrm{u}}(\mathrm{k})$

Example 2: Conservatism of the quadratic approach: Let us consider the following discrete multimodel, composed of three local models and comprising one single output and three states: 


$$
\left\{\begin{aligned}
\mathrm{x}(\mathrm{k}+1) & =\sum_{\mathrm{i}=1}^{2} \mu_{\mathrm{i}}(\xi(\mathrm{k}))\left(\begin{array}{l}
\mathrm{A}_{\mathrm{i}} \mathrm{x}(\mathrm{k})+\mathrm{B}_{\mathrm{i}} \mathrm{u}(\mathrm{k}) \\
+\mathrm{R}_{\mathrm{i}} \overline{\mathrm{u}}(\mathrm{k})
\end{array}\right) \\
\mathrm{y}(\mathrm{k}) & =\mathrm{Cx}(\mathrm{k})+\mathrm{Fu}(\mathrm{k})
\end{aligned}\right.
$$

In this example, the vector of variable decision $\xi(\mathrm{k})$ is equal to the vector of known inputs $\mathrm{u}(\mathrm{k})$. The numerical values of the matrices $A_{i}, B_{i}, C$ and $F$ are as follows:

$$
\begin{aligned}
\mathrm{A}_{1} & =\left(\begin{array}{cc}
1 & 0 \\
0.1 & 1
\end{array}\right), \mathrm{A}_{2}=\left(\begin{array}{cc}
0.1 & -0.4 \\
0.7 & 0.2
\end{array}\right), \\
\mathrm{B}_{1} & =\left(\begin{array}{c}
1 \\
0.25
\end{array}\right), \mathrm{B}_{2}=\left(\begin{array}{c}
1 \\
0.5
\end{array}\right), \\
\mathrm{R}_{1} & =\left(\begin{array}{c}
1 \\
0.5
\end{array}\right), \mathrm{R}_{2}=\left(\begin{array}{c}
2 \\
0.5
\end{array}\right), \mathrm{C}=\left(\begin{array}{ll}
0 & 1
\end{array}\right), \mathrm{F}=5
\end{aligned}
$$

The multiobserver able to estimate the multimodel (27) state is as follows:

$$
\left\{\begin{aligned}
\mathrm{z}(\mathrm{k}+1) & =\sum_{\mathrm{i}=1}^{2} \mu_{\mathrm{i}}(\xi(\mathrm{k}))\left(\begin{array}{l}
\mathrm{N}_{\mathrm{i}} \mathrm{x}(\mathrm{k})+\mathrm{G}_{\mathrm{i} 1} \mathrm{u}(\mathrm{k}) \\
+\mathrm{G}_{\mathrm{i} 2}+\mathrm{L}_{\mathrm{i}} \mathrm{y}(\mathrm{k})
\end{array}\right) \\
\widehat{\mathrm{x}}(\mathrm{k}) & =\mathrm{z}(\mathrm{k})-\mathrm{Ey}(\mathrm{k})
\end{aligned}\right.
$$
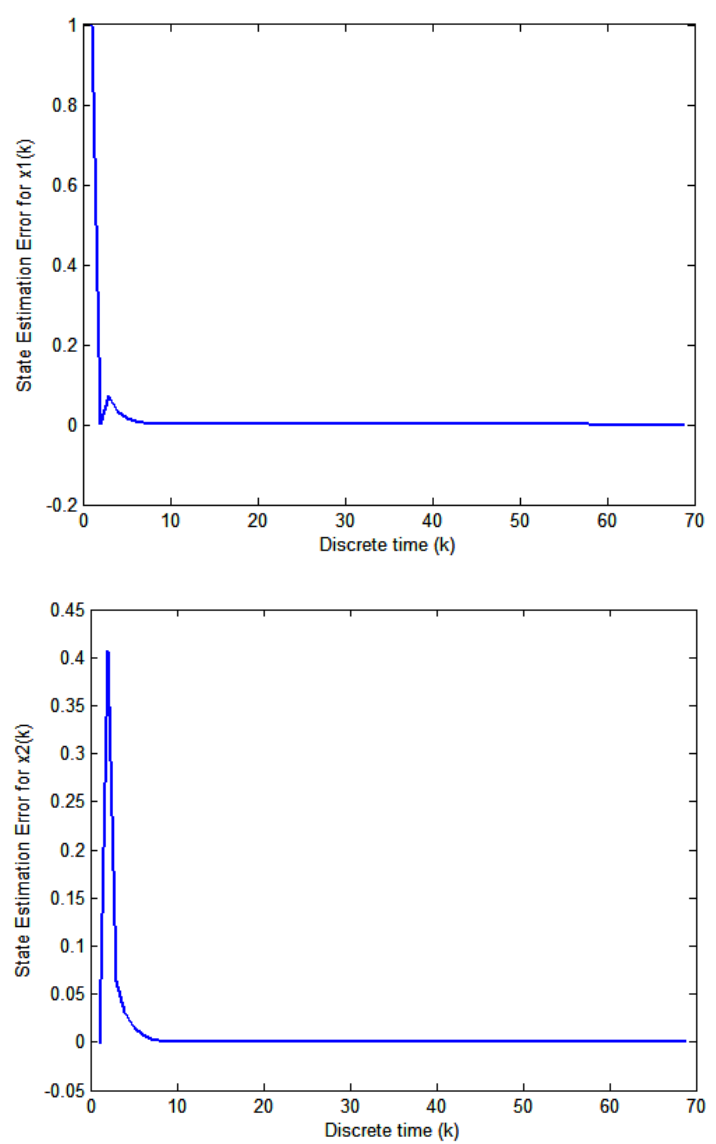

Fig. 3: Estimation errors $e_{i}=x_{i}-\widehat{x}_{i}, i \in\{1,2\}$
The conditions of quadratic stabilization of theorem 2 fails to prove the stabilization of the multiobserver (30), which shows that no quadratic function having the form (17) can exist.

The quadratic approach becomes more and more conservative in the following cases:

- When the number of local models is very important, this is due the difficulty to find one matrix P satisfying all (19) inequalities and equalities

- When the multimodel have local models saturated (the eigenvalues of matrices $A_{i}$ are closer to 1) like the local model number 1 (eigenvalues with $\mathrm{A}_{1}=\{1,1\}$ )

Global convergence of the multiobserver by the piecewise quadratic approach: In this part, the stabilization of the error dynamics (11) depended en the use of piecewise quadratic Lyapunov function of the form:

$\mathrm{V}(\mathrm{x}(\mathrm{k}))=\max \left(\begin{array}{l}\mathrm{V}_{1}(\mathrm{x}(\mathrm{k})), \ldots ., \\ \mathrm{V}_{\mathrm{i}}(\mathrm{x}(\mathrm{k})), \ldots ., \mathrm{V}_{\mathrm{n}}(\mathrm{x}(\mathrm{k}))\end{array}\right)$

Witch:

$\mathrm{V}_{\mathrm{i}}(\mathrm{x}(\mathrm{k}))=\mathrm{x}(\mathrm{k})^{\mathrm{T}} \mathrm{P}_{\mathrm{i}} \mathrm{x}(\mathrm{k}), \mathrm{P}_{\mathrm{i}}>0, \mathrm{i} \in\{1, \ldots, \mathrm{M}\}$

where, $\left(\mathrm{P}_{\mathrm{i}}, \mathrm{i}=1, \ldots, \mathrm{M}\right)$ are symmetric positive definite matrices.

The goal of this second approach is to cure the conservatism of the quadratic approach by formulating new less constraining conditions of stabilization of the observation error (11) by using the following theorem:

Theorem 3: We suppose that there are symmetric positive definite matrices $P_{i}$ and scalars $\tau_{i j k} \geq 0$ such as (Akhenak et al., 2004):

$$
\begin{aligned}
& \mathrm{N}_{\mathrm{i}}^{\mathrm{T}} \mathrm{P}_{\mathrm{j}} \mathrm{N}_{\mathrm{i}}-\mathrm{P}_{\mathrm{j}}+\sum_{\mathrm{k}=1<0, \quad \forall \mathrm{i}, \mathrm{j}, \mathrm{k}}^{\mathrm{M} \tau_{\mathrm{ijk}}\left(\mathrm{P}_{\mathrm{j}}-\mathrm{P}_{\mathrm{k}}\right)} \\
& \in\{1, \ldots, \mathrm{M}\} \quad \text { and } \mathrm{j} \neq \mathrm{k}
\end{aligned}
$$

then the observation error (11) is globally asymptotic stable.

Thus, constraints (33) and (10) allow the complete synthesis of multiobserver (2) for the multimodel (1) with unknown inputs.

Proposition 1: The state estimation error between the multimodel (1) and the unknown input multiobserver (2) converges globally asymptotically towards zero, if all the pairs $\left(\mathrm{A}_{\mathrm{i}}, \mathrm{C}\right)$ are observable and if there exist 
symmetric positive definite matrices $\mathrm{P}_{(\mathrm{i}, \mathrm{j}, \mathrm{k})}$ and matrices $\mathrm{M}_{\mathrm{j}}$ and $\mathrm{H}_{\mathrm{ji}}$ of appropriate dimensions such that the following conditions hold $\forall(\mathrm{i}, \mathrm{j}$, $\mathrm{k}) \in\{1, \ldots, \mathrm{M}\}$ and $\mathrm{j} \neq 1$ :

$$
\begin{aligned}
& \left(\begin{array}{cc}
P_{j}-\sum_{k=1}^{M} \tau_{i j k}\left(P_{j}-P_{k}\right) & \left(P_{j} A_{i}+\right. \\
P_{j} A_{i}+M_{j} C A_{i}-H_{j i} C & \left.H_{j i} C\right)^{T}
\end{array}\right) \\
& >0 \\
& \operatorname{rank}\left(P \quad H_{i}\right)=\operatorname{rank}(P) \\
& \left(P_{j}+M_{j} C\right) R_{i}=H_{j i} F \\
& M_{j} F=0
\end{aligned}
$$
by:

$$
\mathrm{E}=\mathrm{P}_{\mathrm{j}}^{-1} \mathrm{M}_{\mathrm{j}}
$$$$
\mathrm{G}_{\mathrm{i1}}=(\mathrm{I}+\mathrm{EC}) \mathrm{B}_{\mathrm{i}}
$$

$\mathrm{G}_{\mathrm{i} 2}=0$

$$
\mathrm{N}_{\mathrm{i}}=(\mathrm{I}+\mathrm{EC}) \mathrm{A}_{\mathrm{i}}-\left(\mathrm{P}^{-} \mathrm{H}_{\mathrm{i}}\right) \mathrm{C}
$$

$$
\mathrm{L}_{\mathrm{i}}=\left(\mathrm{P}^{-} \mathrm{H}_{\mathrm{i}}\right)-\mathrm{N}_{\mathrm{i}} \mathrm{E}
$$

With:

$$
\mathrm{P}=\left[\begin{array}{c}
\mathrm{P}_{1} \\
\mathrm{P}_{2} \\
\cdot \\
\cdot \\
\mathrm{P}_{\mathrm{M}}
\end{array}\right] \text { and } \mathrm{H}_{\mathrm{i}}=\left[\begin{array}{c}
\mathrm{H}_{1 \mathrm{i}} \\
\mathrm{H}_{2 \mathrm{i}} \\
\cdot \\
\cdot \\
\mathrm{H}_{\mathrm{Mi}}
\end{array}\right] \forall \mathrm{i} \in\{1, \ldots, \mathrm{M}\}
$$

Proof: The studied multiobserver is the result of $\mathrm{M}$ aggregated linear observer. The observability of multimodel (1) is guaranteed if every local model is observable, in other terms is $\left(\mathrm{A}_{\mathrm{j}}, \mathrm{C}\right)$ pairs are observable.

After the multiplication on the left and on the right by -1 , the matrix inequality (33) can be rewritten in the following form:

$$
\begin{aligned}
& \mathrm{P}_{\mathrm{j}}-\sum_{\mathrm{k}=1}^{\mathrm{M}} \tau_{\mathrm{ijk}}\left(\mathrm{P}_{\mathrm{j}}-\mathrm{P}_{\mathrm{k}}\right)-\mathrm{N}_{\mathrm{i}}^{\mathrm{T}} \mathrm{P}_{\mathrm{j}} \mathrm{N}_{\mathrm{i}}, \forall(\mathrm{i}, \mathrm{j}) \\
& \text { and } \mathrm{j} \neq \mathrm{k}
\end{aligned}
$$

We multiply the matrix $P_{j}$ of the last term of the matrix inequality (36) by $\left(\mathrm{P}_{\mathrm{j}}^{-1} \mathrm{P}_{\mathrm{j}}\right)$, we obtain:

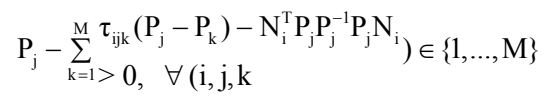

and $\mathrm{j} \neq \mathrm{k}$

Knowing that $(\mathrm{AB})^{\mathrm{T}}=\mathrm{B}^{\mathrm{T}} \mathrm{A}^{\mathrm{T}}$ and $(\mathrm{A}+\mathrm{B})^{\mathrm{T}}=$ $A^{T}+B^{T}$, constraint (37) can be rewritten as follows:

$\mathrm{P}_{\mathrm{j}}-\sum_{\mathrm{k}=1}^{\mathrm{M}} \tau_{\mathrm{ijk}}\left(\mathrm{P}_{\mathrm{j}}-\mathrm{P}_{\mathrm{k}}\right)-\left(\mathrm{P}_{\mathrm{j}} \mathrm{N}_{\mathrm{i}}\right)^{\mathrm{T}} \mathrm{P}_{\mathrm{j}}^{-1}\left(\mathrm{P}_{\mathrm{j}} \mathrm{N}_{\mathrm{i}}\right)$
$\mathrm{i}, \mathrm{j}, \mathrm{k})$

$\in\{1, \ldots, \mathrm{M}\}$

and $\mathrm{j} \neq \mathrm{k}$

The use of the complement of Schur allows expressing the constraints (38) in the following equivalent forms:

$$
\begin{aligned}
& \left(\begin{array}{cc}
P_{j}-\sum_{k=1}^{M} \tau_{i j k}\left(P_{j}-P_{k}\right) & \left(P_{j} N_{i}\right)^{T} \\
P_{j} N_{i} & P_{j}
\end{array}\right) \\
& >0 \quad \forall(i, j, k) \in\{1, \ldots, M\} \text { and } j \neq k
\end{aligned}
$$
obtain:

After using Eq. 5 and 10a into inequality 39, we

$$
\begin{gathered}
\left(\begin{array}{cc}
\mathrm{P}_{\mathrm{j}}-\sum_{\mathrm{k}=1}^{\mathrm{M}} \tau_{\mathrm{ijk}}\left(\mathrm{P}_{\mathrm{j}}-\mathrm{P}_{\mathrm{k}}\right) & \left(\mathrm{P}_{\mathrm{j}} \mathrm{A}_{\mathrm{i}}+\mathrm{P}_{\mathrm{j}} \mathrm{ECA}_{\mathrm{i}}\right. \\
\left.-\mathrm{P}_{\mathrm{j}} \mathrm{K}_{\mathrm{i}} \mathrm{C}\right)^{\mathrm{T}} \\
\mathrm{P}_{\mathrm{j}} \mathrm{A}_{\mathrm{i}}+\mathrm{P}_{\mathrm{j}} \mathrm{ECA}_{\mathrm{i}}-\mathrm{P}_{\mathrm{j}} \mathrm{K}_{\mathrm{i}} \mathrm{C} & \mathrm{P}_{\mathrm{j}}
\end{array}\right) \\
>0 \quad \forall(\mathrm{i}, \mathrm{j}, \mathrm{k}) \in\{1, \ldots, \mathrm{M}\} \text { and } \mathrm{j} \neq \mathrm{k}
\end{gathered}
$$

However, this last inequality (40) is a bilinear matrix inequality BMI in synthesis variables $P_{j}, E, K_{i}$ and $\tau_{\mathrm{ijk}}$. We consider the following changes of variables:

$\mathrm{H}_{\mathrm{ji}}=\mathrm{P}_{\mathrm{j}} \mathrm{K}_{\mathrm{i}}$

$\mathrm{M}_{\mathrm{j}}=\mathrm{P}_{\mathrm{j}} \mathrm{E}$

Using the new variables of Eq. 41 and 42, inequality (40) becomes:

$$
\begin{aligned}
& \left(\begin{array}{cc}
\mathrm{P}_{\mathrm{j}}-\sum_{\mathrm{k}=1}^{\mathrm{M}} \tau_{\mathrm{ijk}}\left(\mathrm{P}_{\mathrm{j}}-\mathrm{P}_{\mathrm{k}}\right) & \left(\mathrm{P}_{\mathrm{j}} \mathrm{A}_{\mathrm{i}}+\mathrm{M}_{\mathrm{j}} \mathrm{CA} \mathrm{A}_{\mathrm{i}}\right. \\
\left.-\mathrm{H}_{\mathrm{ji}} \mathrm{C}\right)^{\mathrm{T}} \\
\mathrm{P}_{\mathrm{j}} \mathrm{A}_{\mathrm{i}}+\mathrm{M}_{\mathrm{j}} \mathrm{CA} A_{\mathrm{i}}-\mathrm{H}_{\mathrm{ji}} \mathrm{C} & \mathrm{P}_{\mathrm{j}}
\end{array}\right) \\
& >0 \quad \forall(\mathrm{i}, \mathrm{j}, \mathrm{k}) \in\{1, \ldots, \mathrm{M}\} \text { and } \mathrm{j} \neq \mathrm{k}
\end{aligned}
$$

The tow equalities constraints (34c) and (34d) are obtained by pre-multiplying the last two constraints (10c) and (10e) by $\mathrm{P}_{\mathrm{j}}$ with the change of variable (41) and (42): 


$$
\begin{aligned}
& \left\{\begin{array} { l } 
{ \mathrm { P } _ { \mathrm { j } } \mathrm { QR } _ { \mathrm { i } } = \mathrm { P } _ { \mathrm { j } } \mathrm { K } _ { \mathrm { i } } \mathrm { F } } \\
{ \mathrm { P } _ { \mathrm { j } } \mathrm { EF } = 0 }
\end{array} \Rightarrow \left\{\begin{array}{l}
\mathrm{P}_{\mathrm{j}}(\mathrm{I}+\mathrm{EC}) \mathrm{R}_{\mathrm{i}}=\mathrm{P}_{\mathrm{j}} \mathrm{K}_{\mathrm{i}} \mathrm{F} \\
\mathrm{M}_{\mathrm{j}} \mathrm{F}=0
\end{array}\right.\right. \\
& \Rightarrow\left\{\begin{array}{l}
\left(\mathrm{P}_{\mathrm{j}}+\mathrm{M}_{\mathrm{j}} \mathrm{C}\right) \mathrm{R}_{\mathrm{i}}=\mathrm{H}_{\mathrm{ji}} \mathrm{F} \\
\mathrm{M}_{\mathrm{j}} \mathrm{F}=0
\end{array} \forall \mathrm{i} \in\{1, \ldots, \mathrm{M}\}\right.
\end{aligned}
$$

The matrix inequalities (40) obtained is a BMI with $\mathrm{P}_{\mathrm{j}}$ and $\mathrm{K}_{\mathrm{i}}$ that we must linearize. The technique chosen is based on the changes of variables (41).

With the expression of $\mathrm{H}_{\mathrm{ji}}$ (41) $\forall(\mathrm{i}, \mathrm{j}$, $\mathrm{k}) \in\{1, \ldots, \mathrm{M}\}$ and $\mathrm{j} \neq \mathrm{k}$, we can write the relations as follows:

$$
\begin{aligned}
& \left.\begin{array}{c}
\mathrm{H}_{11}=\mathrm{P}_{1} \mathrm{~K}_{1} \\
\mathrm{H}_{21}=\mathrm{P}_{2} \mathrm{~K}_{1} \\
\cdot \\
\mathrm{H}_{\mathrm{M} 1}=\mathrm{P}_{\mathrm{M}} \mathrm{K}_{1}
\end{array}\right\} \Rightarrow\left[\begin{array}{c}
\mathrm{H}_{11} \\
\mathrm{H}_{21} \\
\cdot \\
\cdot \\
\mathrm{H}_{\mathrm{M} 1}
\end{array}\right]=\left[\begin{array}{c}
\mathrm{P}_{1} \\
\mathrm{P}_{2} \\
\cdot \\
\cdot \\
\mathrm{P}_{\mathrm{M}}
\end{array}\right] \mathrm{K}_{1} \\
& \left.\begin{array}{c}
\mathrm{H}_{12}=\mathrm{P}_{1} \mathrm{~K}_{2} \\
\mathrm{H}_{22}=\mathrm{P}_{2} \mathrm{~K}_{2} \\
\cdot \\
\cdot \\
\mathrm{H}_{\mathrm{M} 2}=\mathrm{P}_{\mathrm{M}} \mathrm{K}_{2}
\end{array}\right\} \Rightarrow\left[\begin{array}{c}
\mathrm{H}_{12} \\
\mathrm{H}_{22} \\
\cdot \\
\cdot \\
\mathrm{H}_{\mathrm{M} 2}
\end{array}\right]=\left[\begin{array}{c}
\mathrm{P}_{1} \\
\mathrm{P}_{2} \\
\cdot \\
\cdot \\
\mathrm{P}_{\mathrm{M}}
\end{array}\right] \mathrm{K}_{2}
\end{aligned}
$$

$\left.\begin{array}{c}\mathrm{H}_{1 \mathrm{M}}=\mathrm{P}_{1} \mathrm{~K}_{\mathrm{M}} \\ \mathrm{H}_{2 \mathrm{M}}=\mathrm{P}_{2} \mathrm{~K}_{\mathrm{M}} \\ \cdot \\ \mathrm{H}_{\mathrm{MM}}=\mathrm{P}_{\mathrm{M}} \mathrm{K}_{\mathrm{M}}\end{array}\right\}\left[\begin{array}{c}\mathrm{H}_{1 \mathrm{M}} \\ \mathrm{H}_{2 \mathrm{M}} \\ \cdot \\ \cdot \\ \mathrm{H}_{\mathrm{MM}}\end{array}\right]=\left[\begin{array}{c}\mathrm{P}_{1} \\ \mathrm{P}_{2} \\ \cdot \\ \cdot \\ \mathrm{P}_{\mathrm{M}}\end{array}\right] \mathrm{K}_{\mathrm{M}}$

We pose:

$$
\mathrm{P}=\left(\begin{array}{c}
\mathrm{P}_{1} \\
\mathrm{P}_{2} \\
\cdot \\
\cdot \\
\mathrm{P}_{\mathrm{M}}
\end{array}\right) \text { and } \mathrm{H}_{\mathrm{i}}=\left(\begin{array}{c}
\mathrm{H}_{1 \mathrm{i}} \\
\mathrm{H}_{2 \mathrm{i}} \\
\cdot \\
\cdot \\
\mathrm{H}_{\mathrm{Mi}}
\end{array}\right) \forall \mathrm{i} \in\{1, \ldots, \mathrm{M}\}
$$

From the Eq. (44-47) we can deduce:

$\mathrm{H}_{\mathrm{i}}=\mathrm{PK}_{\mathrm{i}} \Rightarrow \mathrm{K}_{\mathrm{i}}=\mathrm{P}^{-} \mathrm{H}_{\mathrm{i}} \forall \mathrm{i} \in\{1, \ldots, \mathrm{M}\}$

However the gains $\mathrm{K}_{\mathrm{i}}$ of the Eq. 48 can exist only if the following condition of rank is satisfied:

$\operatorname{rank}\left(\mathrm{P} \quad \mathrm{H}_{\mathrm{i}}\right)=\operatorname{rank}(\mathrm{P}) \forall_{\mathrm{i}} \in\{1, \ldots, \mathrm{M}\}$
The conditions (34a-d) of proposition 1 are verified.

Therefore classical numerical tools may be used to solve LMI problem (34a) subject to linear equality constraints (34b-d). After having solved this problem, the different gains matrices defining the multiobserver (2) $\mathrm{N}_{\mathrm{i}}, \mathrm{L}_{\mathrm{i}}, \mathrm{G}_{\mathrm{i} 1}, \mathrm{G}_{\mathrm{i} 2}$ and $\mathrm{E}$ can be deduced from the knowledge of $\mathrm{P}_{(\mathrm{i}, \mathrm{j}, \mathrm{k})}, \mathrm{H}_{\mathrm{ji}}$ and $\mathrm{M}_{\mathrm{i}}$ as given in Eq. 35. This completes the proof of proposition 1.

Remark 3: The matrix inequality (34a) presents two not convex problems. The first appeared in the bilinear of the matrix inequality (34a) in $\left(\tau_{\mathrm{ijk}}, \mathrm{P}_{\mathrm{j}}\right)$ and $\left(\tau_{\mathrm{ijk}}, \mathrm{P}_{\mathrm{k}}\right) \forall(\mathrm{i}, \mathrm{j}, \mathrm{k}) \in\{1, \ldots, \mathrm{M}\}$ and $\mathrm{j} \neq \mathrm{k}$. The second is shown on the level of the resolution of matrix inequality (34a) under the constraint of rank (34b).

Treatment of the not convex problems: Obtaining the solutions to the matrix inequality (34a) requires first of all the treatment of not convexities of two problems presented previously. For that we give some methods used by researchers to solve this kind of problems.

Linearization of matrix inequality Bilinear: The linearization of the bilinear matrix inequality (34a) in $\left(\tau_{\mathrm{ijk}}, \mathrm{P}_{\mathrm{j}}\right)$ and $\left(\tau_{\mathrm{ijk}}, \mathrm{P}_{\mathrm{k}}\right) \forall(\mathrm{i}, \mathrm{j}, \mathrm{k}) \in\{1, \ldots, \mathrm{M}\}$ and $\mathrm{j} \neq \mathrm{k}$ can be made by the application of an iterative algorithm of initialization of the positive scalars $\tau_{\mathrm{ijk}} \geq 0$ or by their fixing (Chadli et al., 2002).

Treatment of the constraint of rank: After having to linearize the matrix inequality (34a), it is necessary to solve the latter with the constraint of rank (34b) and that is a not convex problem difficult to solve. However, several authors proposed iterative algorithms to release this kind of problems like (Tanaka and Sugeno, 1992). As an example, in (Henrion et al., 2000) the author proposed an iterative algorithm of relaxation which consists in solving a LMI with a constraint of rank.

Determination of the multiobserver gain matrices: To determine the multiobserver (2) gain matrices by piecewise quadratic approach, we propose to follow the steps of the following algorithm:

Step 1: Determination of the matrices $\mathrm{P}_{(\mathrm{i}, \mathrm{j}, \mathrm{k})}, \mathrm{H}_{\mathrm{ji}}$ and $\mathrm{M}_{\mathrm{j}}, \forall(\mathrm{i}, \mathrm{j}, \mathrm{k}) \in\{1, \ldots, \mathrm{M}\}$ and $\mathrm{j} \neq \mathrm{k}$.

We solve the Linear Matrix Inequalities (32a) in synthesis variables $\mathrm{P}_{(\mathrm{i}, \mathrm{j}, \mathrm{k})}, \mathrm{H}_{\mathrm{ji}}$ and $\mathrm{M}_{\mathrm{j}}$ subject to linear equality constraints $(34 b-d)$. This problem can be solved by LMITOOL

Step 2: Determination of the gains matrices $\mathrm{N}_{\mathrm{i}}, \mathrm{L}_{\mathrm{i}}$, $\mathrm{G}_{\mathrm{i} 1}, \mathrm{G}_{\mathrm{i} 2}$ and $\mathrm{E}, \forall(\mathrm{i}, \mathrm{j}, \mathrm{k}) \in\{1, \ldots, \mathrm{M}\}$ and $\mathrm{j} \neq \mathrm{k}$ After the knowledge of the matrices $P_{(i, j, k)}$, 
$\mathrm{H}_{\mathrm{ji}}$ and $\mathrm{M}_{\mathrm{j}}$, we determine the other gains matrices of Eq. 35 defining the multiobserver (2)

Remark 4: For a matrix $F$ equal to a scalar, we can deduce the following relations, $\forall(\mathrm{i}, \mathrm{j}, \mathrm{k}) \in\{1, \ldots, \mathrm{M}\}$ and $\mathrm{j} \neq \mathrm{k}$ :

$$
\begin{aligned}
& \mathrm{M}_{\mathrm{j}}=0 \\
& \mathrm{E}=0 \\
& \mathrm{Q}=\mathrm{I} \\
& \mathrm{G}_{\mathrm{i} 1}=\mathrm{B}_{\mathrm{i}} \\
& \mathrm{G}_{\mathrm{i} 2}=0 \\
& \mathrm{~N}_{\mathrm{i}}=\mathrm{A}_{\mathrm{i}}-\mathrm{P}^{-} \mathrm{H}_{\mathrm{i}} \mathrm{C} \\
& \mathrm{L}_{\mathrm{i}}=\left(\mathrm{P}^{-} \mathrm{H}_{\mathrm{i}}\right)=\mathrm{K}_{\mathrm{i}} \\
& \mathrm{R}_{\mathrm{i}}=\mathrm{P}^{-} \mathrm{H}_{\mathrm{i}} \mathrm{F}
\end{aligned}
$$

These relations are given after the resolution of the linear matrix inequality (34a) for $\mathrm{M}_{\mathrm{j}}=0$ in synthesis variables $\mathrm{P}_{(\mathrm{i}, \mathrm{j}, \mathrm{k})}$ and $\mathrm{H}_{\mathrm{ji}}$ :

$$
\begin{gathered}
\left(\begin{array}{cc}
\mathrm{P}_{\mathrm{j}}-\sum_{\mathrm{k}=1}^{\mathrm{M}} \tau_{\mathrm{ijk}}\left(\mathrm{P}_{\mathrm{j}}-\mathrm{P}_{\mathrm{k}}\right) & \left(\mathrm{P}_{\mathrm{j}} \mathrm{A}_{\mathrm{i}}-\mathrm{H}_{\mathrm{ji}} \mathrm{C}\right)^{\mathrm{T}} \\
\mathrm{P}_{\mathrm{j}} \mathrm{A}_{\mathrm{i}}-\mathrm{H}_{\mathrm{ji}} \mathrm{C} & \mathrm{P}_{\mathrm{j}}
\end{array}\right) \\
>0 \quad \forall(\mathrm{i}, \mathrm{j}, \mathrm{k}) \in\{1, \ldots, \mathrm{M}\} \text { and } \mathrm{j} \neq \mathrm{k}
\end{gathered}
$$

Remark 5: It's obvious that the conditions of proposition 1 are less conservative than the conditions depending on the use of a single Lyapunov function. The quadratic conditions stabilization is considered like a particular case of (34a) by composing $\mathrm{P}_{(\mathrm{i}, \mathrm{j}, \mathrm{k})}=\mathrm{P}_{0}$ it follows that $\mathrm{P}_{\mathrm{j}}-\mathrm{P}_{\mathrm{k}}=0$ and the condition of rank (34b) becomes trivial.

Example 3: Application of the piecewise quadratic approach: Let us consider the discrete multi-model of example 2; the conditions of stabilization of proposition 1 prove the stability of the multiobserver (30), what shows that a piecewise quadratic function of the form (31) exists.

By applying the piecewise quadratic approach, we showed global convergence of the multiobserver (30).

The resolution of the conditions of proposition 1 leads to the following result:

With the choice of the parameters:

$$
\tau_{11}=3, \tau_{12}=1, \tau_{21}=0.3, \tau_{22}=0
$$

We obtain four LMI in $\mathrm{P}_{1}, \mathrm{P}_{2}, \mathrm{M}_{1}, \mathrm{M}_{2} \mathrm{H}_{11}, \mathrm{H}_{12}$, $\mathrm{H}_{21}$ and $\mathrm{H}_{22}$ which must be solved under the following rank constraints:

$\operatorname{rank}=\left[\begin{array}{l}\mathrm{P}_{1} \\ \mathrm{P}_{2}\end{array}\right]=\operatorname{rank}\left[\begin{array}{l}\mathrm{H}_{11} \\ \mathrm{H}_{21}\end{array}\right]=\operatorname{rank}\left[\begin{array}{l}\mathrm{H}_{12} \\ \mathrm{H}_{22}\end{array}\right]$

The resolution of the conditions of proposition 1 leads to the following result:

$$
\begin{gathered}
\mathrm{P}_{1}=\left[\begin{array}{cc}
5683.5055 & 908.3627 \\
908.3627 & 4189.8622
\end{array}\right], \\
\mathrm{P}_{2}=\left[\begin{array}{cc}
9070.6173 & 3681.729 \\
3681.729 & 7455.7043
\end{array}\right] \\
\mathrm{M}_{1}=\mathrm{M}_{2}=0: \\
\mathrm{H}_{11}=\left[\begin{array}{c}
1182.1192 \\
391.3313
\end{array}\right], \mathrm{H}_{21}=\left[\begin{array}{c}
1907.3198 \\
745.5706
\end{array}\right], \\
\mathrm{H}_{12}=\left[\begin{array}{c}
2364.2385 \\
782.3313
\end{array}\right], \mathrm{H}_{22}=\left[\begin{array}{l}
3814.6396 \\
1491.1412
\end{array}\right]
\end{gathered}
$$

We can to check that:

$$
\operatorname{rank}=\left[\begin{array}{l}
\mathrm{P}_{1} \\
\mathrm{P}_{2}
\end{array}\right]=\operatorname{rank}\left[\begin{array}{l}
\mathrm{H}_{11} \\
\mathrm{H}_{21}
\end{array}\right]=\operatorname{rank}\left[\begin{array}{l}
\mathrm{H}_{12} \\
\mathrm{H}_{22}
\end{array}\right]=2
$$

After the knowledge of the matrices $\mathrm{P}_{1}, \mathrm{P}_{2}, \mathrm{M}_{1}$, $\mathrm{M}_{2} \mathrm{H}_{11}, \mathrm{H}_{12}, \mathrm{H}_{21}$ and $\mathrm{H}_{22}$ we deduce the other matrices from the profits defining the multiobserver (30):

$$
\begin{gathered}
\mathrm{G}_{11}=\mathrm{B}_{1}=\left[\begin{array}{c}
1 \\
0.5
\end{array}\right] \mathrm{G}_{21}=\mathrm{B}_{2}=\left[\begin{array}{c}
1 \\
0.5
\end{array}\right], \\
\mathrm{K}_{1}=\mathrm{P}^{-} \mathrm{H}_{1}=\left(\left[\begin{array}{l}
\mathrm{P}_{1} \\
\mathrm{P}_{2}
\end{array}\right]\right)^{-}\left[\begin{array}{l}
\mathrm{H}_{11} \\
\mathrm{H}_{21}
\end{array}\right]=\left[\begin{array}{l}
0.2 \\
0.05
\end{array}\right], \\
\mathrm{K}_{2}=\mathrm{P}^{-} \mathrm{H}_{2}=\left(\left[\begin{array}{l}
\mathrm{P}_{1} \\
\mathrm{P}_{2}
\end{array}\right]\right)^{-}\left[\begin{array}{l}
\mathrm{H}_{12} \\
\mathrm{H}_{22}
\end{array}\right]=\left[\begin{array}{l}
0.4 \\
0.1
\end{array}\right] \\
\mathrm{N}_{1}=\mathrm{A}_{1}-\mathrm{K}_{1} \mathrm{C}=\left[\begin{array}{ll}
0.8 & 0 \\
0.05 & 1
\end{array}\right], \\
\mathrm{N}_{2}=\mathrm{A}_{2}-\mathrm{K}_{2} \mathrm{C}=\left[\begin{array}{cc}
-0.3 & -0.4 \\
0.6 & 0.2
\end{array}\right]
\end{gathered}
$$

With $\mathrm{E}=0 \Rightarrow \mathrm{L}_{\mathrm{i}}=\mathrm{K}_{\mathrm{i}}$

$$
\mathrm{L}_{1}=\mathrm{K}_{1}=\left[\begin{array}{l}
0.2 \\
0.05
\end{array}\right] \text { and } \mathrm{L}_{2}=\mathrm{K}_{2}=\left[\begin{array}{l}
0.4 \\
0.1
\end{array}\right]
$$


Figure 4 represent respectively the evolution of the activation functions, the inputs known $\mathrm{u}(\mathrm{k})$ and unknown $\overline{\mathrm{u}}(\mathrm{k})$. As for the Fig. 5, they show the state estimation errors $\left(\mathrm{x}_{\mathrm{i}}(\mathrm{k})-\widehat{\mathrm{x}}_{\mathrm{i}}(\mathrm{k}), \mathrm{i}=\{1,2\}\right)$ as well as the unknown input $\overline{\mathrm{u}}(\mathrm{k})$ of the multimodel and their estimation $\hat{\bar{u}}(\mathrm{k})$. It is noted that the estimation quality is satisfactory except in the vicinity of the time

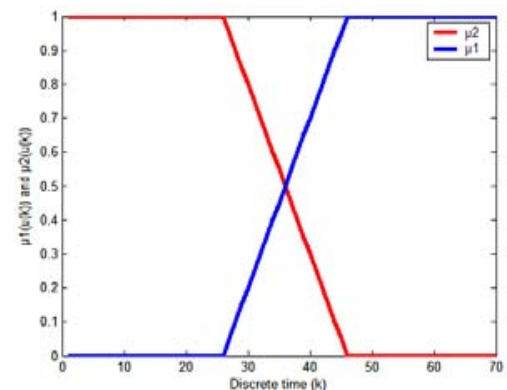

(a) origin; that is due to the choice of the multiobserver (30) initial values $\mathrm{x}_{0}=\left(\begin{array}{ll}0.3 & 0\end{array}\right)^{\mathrm{T}}$ and $\hat{\mathrm{x}}_{0}=\left(\begin{array}{ll}0 & 0\end{array}\right)^{\mathrm{T}}$.

The simulation results presented by the Fig. 5 show that the state estimation as well as the unknown inputs of the multimodel are very satisfying except at the origin of time. This is due to the choices of the initial conditions.

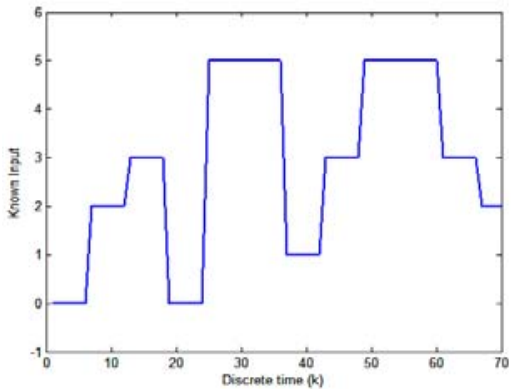

(b)

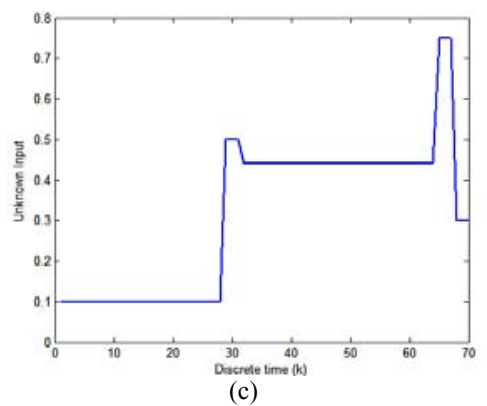

Fig. 4: Functions of activation and input known (a) $\mu_{1}(\mathrm{k})$ and $\mu_{2}(\mathrm{k})$; (b) $\mathrm{u}(\mathrm{k})$ and unknown; (c) $\overline{\mathrm{u}}(\mathrm{k})$

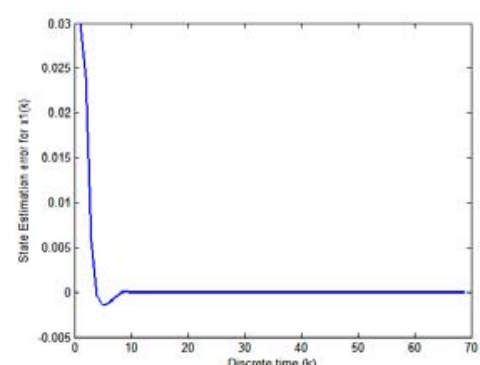

(a)

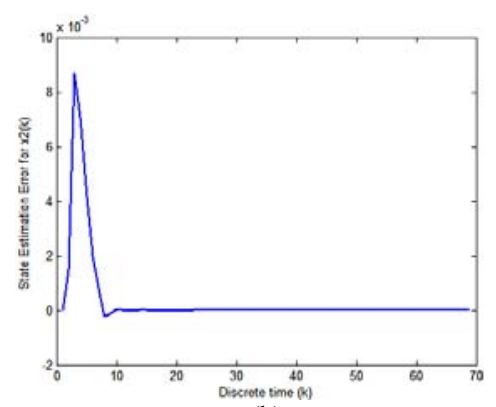

(b)

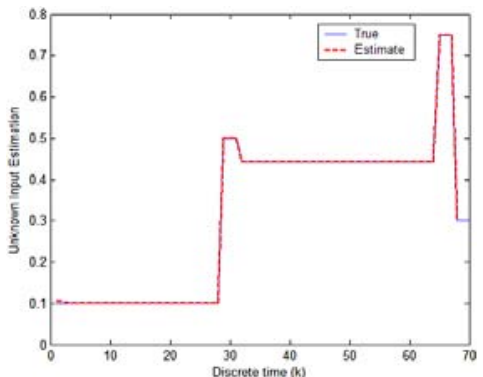

(c)

Fig. 5: Results of the estimates; (a) $\mathrm{x}_{1}(\mathrm{k})-\widehat{\mathrm{x}}_{1}(\mathrm{k})$; (b) $\mathrm{x}_{2}(\mathrm{k})-\widehat{\mathrm{x}}_{2}(\mathrm{k})$ and (c) $\overline{\mathrm{u}}(\mathrm{k})$ et $\overline{\mathrm{u}}(\mathrm{k})$ 


\section{CONCLUSION}

In this article, we presented two stabilization approaches of a multiobserver with unknown inputs for a nonlinear system describes by a discrete multimodel with decision variables measurable. The first approach is based on the use of the Lyapunov quadratic functions, the conditions obtained of this approach for the convergence of the multi-observer are often easy to obtain but they appear pessimistic. The second approach suggested for the stabilization of the observation error, is based on the use of the Lyapunov piecewise quadratic functions. The conditions obtained of the multiobserver convergence are given in the form of Bilinear Matrices Inequalities BMI that we can linearize by the technique of change of variables and easily solve them with the numerical tools traditional. This second approach appears less conservative than the first.

Two illustrative examples are proposed to proof the efficiency and the utility of each of the two approaches. The first example presented showed that the quadratic approach is interesting from point of view of the practical implementation for the supervision and the diagnosis of the industrial processes. The second example put emphases on the important contribution of the piecewise quadratic approach compared to the quadratic approach for the states estimation and unknown inputs of a nonlinear system represented by a discrete multimodel.

The conditions obtained of the two approaches proposed, concern only the study of the multiobserver stabilization with unknown inputs. The poles placement problem, thus the state estimation and unknown inputs in cases where the decision variables are not measurable, can constitute an interesting prospect for this study.

\section{ACKNOWLEDGEMENT}

This research was supported by the Laboratory Networks and Machines Electric of National institute of Sciences Applied and Technologies of Tunis.

\section{REFERENCES}

Akhenak, A., M. Chadli, D. Maquin and J. Ragot, 2003. State estimation via multiple observer with unknown inputs: Application to the three tank system. Proceeding of the 5th IFAC Symposium on Fault Detection Supervision and Safety for Technical Processes, June 9-11, Safeprocess, Washington, USA., pp: 1227-1232.

Akhenak, A., M. Chadli, D. Maquin and J. Ragot, 2004. State estimation of uncertain multiple model with unknown inputs. Proceeding of the 43rd IEEE Conference on Decision and Control, Dec. 14-17, IEEE Xplore Press, USA., pp: 3563-3568. DOI: $10.1109 /$ CDC.2004.1429265
Akhenak, A., M. Chadli, J. Ragot and D. Maquin, 2006. Unknown input multiple observer basedapproach-application to secure communications. Proceeding of the 1st Conference on Analysis and control of Chaotic Systems, Dec., 9-12, IFAC, Hawaii, USA., pp: 953-958. http://hal.archivesouvertes.fr/docs/00/09/20/56/PDF/ifac_chaos06. pdf

Athamena, B., Z. Houhamdi and M. Muhairat, 2007. Fault detection and isolation in dynamic systems using statistical local approach and hybrid least squares algorithm. Am. J. Applied Sci., 4: 977-986. DOI: 10.3844/ajassp.2007.977.986

Chadli, M. and A. El Ahajjaji, 2006. Comment on "Observer-based robust fuzzy control of nonlinear systems with parametric uncertainties". Fuzzy Sets Syst., 157: 1276-1281. DOI: 10.1016/j.fss.2005.09.004

Chadli, M., A. Akhenak, J. Ragot and D. Maquin, 2009. State and unknown input estimation for discrete time multiple model. J. Franklin Inst. 346: 593-610. DOI: 10.1016/j.jfranklin.2009.02.011

Chadli, M., D. Maquin and J. Ragot, 2002. Nonquadratic stability of Takagi-Sugeno systems. Proceeding of the IEEE 41th CDC, Mar. 21-23, IEEE Computer Society, Las Vegas, Nevada, pp: 1315-1320.

Daafouz, J. and J. Bernussou, 2001. Parameter dependent Lyapunov functions for discrete time systems with time varying parametric uncertainties. Syst. Control Lett., 43: 355359. DOI: 10.1016/S0167-6911(01)00118-9

Darouach, M., M. Zasadzinski and S.J. Xu, 1994. Full-order observers for linear systems with unknown inputs. IEEE Trans. Autom. Control, 39: 606-609. DOI: 10.1109/9.280770

Dassanake, S.K., G.L. Balas and J. Bokor, 2000. Using unknown input observers to detect and isolate sensor faults in a turbofan engine. Proceeding of the Digital Avionics System Conference, Oct. 7-13, IEEE Xplore Press, Philadelphia, PA., USA., pp: 6E51-6E57. DOI: 10.1109/DASC.2000.884916

Floquet, T. and J.P. Barbot, 2004. A sliding mode approach of unknown input observers for linear systems. Proceeding of the IEEE Conference on Decision and Control, Man and Cybernetics, Dec. 14-17, IEEE Xplore Press, USA., pp: 1724-1729. DOI: 10.1109/CDC.2004.1430293

Gasso, K., G. Mourot and J. Ragot, 2001. Structure identification in multiple model representation: Elimination and merging of local models. Proceeding of the IEEE Conference on Decision and Control, Man and Cybernetics, Dec. 4-7, Orlando, FL., USA., pp: 2992-2997. DOI: 10.1109/.2001.980732 
Hakiki, K., B. Mazari, A. Liazid and S. Djaber, 2006. Fault reconstruction using sliding mode observers. Am. J. Applied Sci., 3: 1669-1674. DOI: 10.3844/ajassp.2006.1669.1674

Henrion, D., V. Kucera and M. Sebek, 2000. Stabilization of affine polynomial families: An LMI approach. Proceedings of the 2000 IEEE Internationnal Symposium on Computer-Aided Control System Design, Sept. 25-27, IEEE Xplore Press, Anchorage, AK., USA., pp: 54-59. DOI: $10.1109 /$ CACSD.2000.900186

Jadbabaie, A., 1999. A reduction in conservatism in stability and L2 gain analysis of Takagi-Sugeno fuzzy systems via linear matrix inequalities. Proceedings of the International Federation Automatic Control, (IFAC'99), IEEE Computer Society, China, pp: 285-289.

Johansen, T.A. and R. Babuska, 2003. Multiobjective identification of Takagi-Sugeno fuzzy models. IEEE Trans. Fuzzy Syst., 11: 847-860. DOI: 10.1109/TFUZZ.2003.819824

Johansen, T.A., 2000. Computation of Lyapunov functions for smooth nonlinear systems using convex optimization. Automatica, 36: 1617-1626. DOI: 10.1016/S0005-1098(00)00088-1

Johansen, T.A., R. Shorten and R. Murray-Smith, 2000. On the interpretation and identification of dynamic Takagi-Sugeno fuzzy models. IEEE Trans. Fuzzy Syst., 8: 297-313. DOI: $10.1109 / 91.855918$

Johansson, M., A. Rantzer and K.E. Arzen, 1999. Piecewise quadratic stability of fuzzy systems. IEEE Trans. Fuzzy Syst., 7: 713-722. DOI: 10.1109/91.811241

Kechida, S. and N.E. Debbache, 2005. Failure diagnosis on discrete event systems. Am. J. Applied Sci., 2: 1547-1551. DOI: 10.3844/ajassp.2005.1547.1551

Koeing, D., 2006. Observer design for unknown input nonlinear descriptor systems via convex optimization. IEEE Trans. Autom. Control, 51: 1047-1052. DOI: 10.1109/TAC.2006.876807
Kim, S.J., Y.H. Moon and S. Kwon, 2006. Simultaneous stabilization by static output feedback: A rank-constrained LMI approach. Proceeding of the 45th IEEE Conference on Decision and Control, Dec. 13-15, IEEE Xplore Press, San Diego, CA., pp: 5162-5167. DOI: 10.1109/CDC.2006.376683

Moreno, J., 2001. Quasi-Unknown input observers for linear systems. Proceeding of the IEEE Conference on Control Applications, Sept. 5-7, IEEE Xplore Press, Mexico City, Mexico, pp: 732-737. DOI: 10.1109/CCA.2001.973955

Maherzi, E., M. Besbes, M. Ellouze and R. Mhiri, 2007. Polyquadratic stabilization of a multiinputs multimodel with quantified commands. Int. J. Circ., Syst. Sign. Process., 1: 22-27. http://www.naun.org/journals/circuitssystemssig nal/cssp-5.pdf

Marx, B., D. Koenig and J. Ragot, 2007. Design of observers for Takagi-Sugeno descriptor systems with unknown inputs and application to fault diagnosis. IET Control Theory Appli., 1: 1487-1495.

Patton, R.J., J. Chen and C.J. Lopez-Toribio, 1998. Fuzzy observers for nonlinear dynamic systems fault diagnosis. Proceeding of the 37th IEEE Conference on Decision and Control, Dec. 16-18, IEEE Xplore Press, Tampa, FL., USA., pp: 84-89. DOI: 10.1109/CDC.1998.760594

Tanaka, K. and M. Sugeno, 1992. Stability analysis and design of fuzzy control systems. Fuzzy Sets Syst., 45: 135-156. DOI: 10.1016/01650114(92)90113-I

Tanaka, K., T. Ikeda and H.O. Wang, 1998. Fuzzy regulators and fuzzy observers: Relaxed stability conditions and LMI-based designs. IEEE Trans. Fuzzy Syst., 6: 250-265. DOI: 10.1109/91.669023

Vandenberghe, L. and S. Boyd, 1996. Semidefinite programming. SIAM Rev., 38: 49-95. http://www.jstor.org/pss/2132974 